\title{
Combination Phototherapy with a Histone Deacetylase Inhibitor and a Potent DNA-Binding Bibenzimidazole: Effects in Haematological Cell Lines
}

\author{
Annabelle L. Rodd, ${ }^{1,2}$ Katherine Ververis, ${ }^{1,2}$ and Tom C. Karagiannis ${ }^{1,2}$ \\ ${ }^{1}$ Epigenomic Medicine Laboratory, Baker IDI Heart and Diabetes Institute, The Alfred Medical Research and Education Precinct, \\ 75 Commercial Road, Melbourne, VIC 3004, Australia \\ ${ }^{2}$ Department of Pathology, The University of Melbourne, Parkville, VIC 3010, Australia
}

Correspondence should be addressed to Tom C. Karagiannis, tom.karagiannis@bakeridi.edu.au

Received 30 May 2012; Accepted 15 August 2012

Academic Editor: Vincent Ribrag

Copyright (C) 2012 Annabelle L. Rodd et al. This is an open access article distributed under the Creative Commons Attribution License, which permits unrestricted use, distribution, and reproduction in any medium, provided the original work is properly cited.

Current treatment for cutaneous T-cell lymphoma includes phototherapy, which involves either the use of narrowband ultraviolet B light or $\mathrm{UV}_{\mathrm{A}}$ in combination with a psoralen photosensitiser. Therapy typically involves administration of the photosensitiser followed by topical exposure to $\mathrm{UV}_{\mathrm{A}}$. A different approach is extracorporeal photopheresis, an ex vivo strategy which is used for more advanced stages of disease. Further, histone deacetylase inhibitors are emerging as potent anticancer agents with suberoylanilide hydroxamic acid and depsipeptide, having received FDA approval for the treatment of cutaneous T-cell lymphoma. We have developed $\mathrm{UV}_{\mathrm{A}}$ Sens, an extremely potent, DNA minor groove-binding $\mathrm{UV}_{\mathrm{A}}$ sensitizer for potential use in phototherapy. We have previously demonstrated the extreme photopotency of $\mathrm{UV}_{\mathrm{A}}$ Sens in human erythroleukemic K562 cells. Here we have extended those studies by investigating the photopotency of $\mathrm{UV}_{\mathrm{A}}$ Sens in four haematological cell lines, namely, K562, T-cell leukaemic CEM-CCRF, P-glycoprotein overexpressing R100, and transformed B-lymphoblastoid cell lines (LCL) cells. In addition, we investigated the effects of suberoylanilide hydroxamic acid in combination with $\mathrm{UV}_{\mathrm{A}}$ Sens. Using $\gamma \mathrm{H} 2 \mathrm{AX}$ as the endpoint, our findings indicate that $\mathrm{UV}_{\mathrm{A}}$ Sens-induced phototoxicity in all four of the haematological cell lines. The addition of suberoylanilide hydroxamic acid augmented the photopotency of $\mathrm{UV}_{\mathrm{A}}$ Sens highlighting the potential clinical applicability of combination therapies.

\section{Introduction}

Cutaneous T-cell lymphoma (CTCL) describes a heterogenous series of extranodal non-Hodgkin T-cell lymphomas that primarily appear in the skin $[1,2]$. CTCL is characterised by an initial influx of T-cells of the CD4 phenotype in the skin, which have the propensity to home and accumulate in the blood and lymph nodes as the disease develops [2-4]. The two most common subtypes of CTCL include mycosis fungoides (MF), generally a low-grade lymphoma characterised by skin manifestations and the erythrodermic version Sézary syndrome. Sézary syndrome is an aggressive leukemic form of the disease identifiable by diffuse skin involvement (erythroderma), lymphadenopathy, and the presence of abnormal lymphoid cells circulating in the blood
$[5,6]$. Although a rare condition, with annual incidence of approximately $0.2-0.8$ per $100,000[7,8]$, in its advanced or transformed stages, it is a debilitating disease, differing dramatically in its clinical and histopathologic presentations and subsequent therapeutic considerations [9]. While a plethora of treatments are available for CTCL, most remain palliative, and prolonged remissions or cures are rare for advanced stages of the disease.

While the idea of phototherapy has been acknowledged for hundreds of years, the concept of using phototherapy for the treatment of CTCL came to the forefront in the early 1970s. Phototherapy involves the combined use of nonionising electromagnetic energy together with a photosensitising chemical compound-a phenomenon known as photochemotherapy. Currently PUVA therapy is a common 


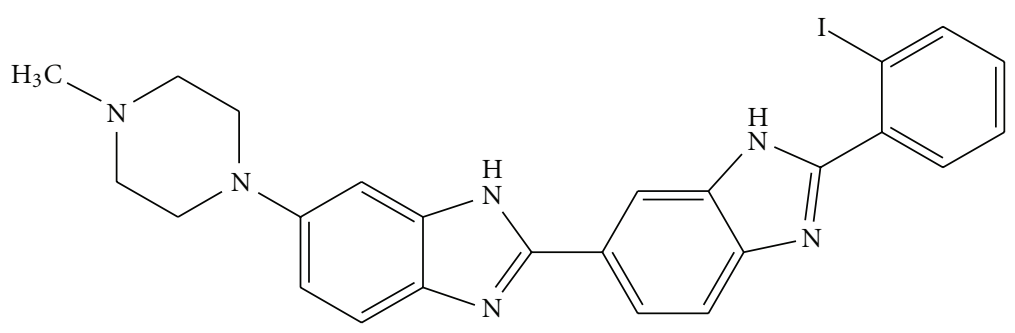

FIGURE 1: Chemical structure of $\mathrm{UV}_{\mathrm{A}}$ Sens (ortho-iodo-Hoechst).

avenue of therapy for a variety of hyperproliferative skin diseases including psoriasis and early stages of CTCL. This involves the pretreatment with a psoralen (typically 8methoxypsoralen; 8-MOP), prior to long-wave ultraviolet radiation (320-400 nm, $\mathrm{UV}_{\mathrm{A}}$ ) exposure. Psoralens directly intercalate into DNA, and upon exposure to $\mathrm{UV}_{\mathrm{A}}$ radiation become photoexcited leading to the formation of a photoadduct which interferes with DNA synthesis [10]. At more advanced stages of CTCL, once the T-cells are no longer dependent on the keratinocytes and begin to migrate to the lymph nodes and peripheral blood, systemic treatment is warranted. At this stage, extracorporeal photopheresis (ECP) may become a therapeutic option. ECP involves the direct administration of 8-MOP into the plasma fraction of the blood, followed by exposure of the photosensitised peripheral blood mononuclear cells to $\mathrm{UV}_{\mathrm{A}}$ irradiation, ex vivo [11]. In addition to the mechanisms of action associated with PUVA, an immunomodulatory response is believed to be responsible for the beneficial actions behind ECP. Specifically this response is believed to involve dendritic cell maturation, stimulation of T-regulatory lymphocytes and modulation of T-helper cells [11-14].

Halogenated DNA precursors are an additional set of photosensitisers that have been investigated for their potential use in phototherapy. These UV sensitisers, specifically iodo- and bromodeoxyuridine, are pyrimidine analogues that have been prepared with a halogen substituted in place of the methyl group of thymidine. These results in the analogues compete with thymidine during DNA synthesis and subsequently leading to the insertion of a halogen atom into DNA. Intercalation results in sensitisation of DNA to both UVB irradiation and ionising radiation [14]. Photoactivation of these compounds in DNA results in photodehalogenation-the dissociation of the carbon-halogen bond, followed by uracilyl free radical formation. This causes abstraction of $\mathrm{H}$ atoms from deoxyribosyl carbons, subsequently inducing DNA strand breakage. While these halogenated DNA precursors have shown to be effective, one major concern is that they are only incorporated into the synthesis phase ( $\mathrm{S}$ phase) of the cell cycle, limiting the population of cells that are sensitised [15]. The limitation of halogenated pyrimidine analogues described above has prompted the investigation of alternative photosensitisers, such as iodinated DNA minor groove-binding bibenzimidazoles [16].
A series of iodinated bis-benzimidazoles have been extensively investigated for their $\mathrm{UV}_{\mathrm{A}}$ photosensitisation properties [17]. Studies have highlighted the photopotency of directly iodinated Hoechst 33258 (prepared by direct iodination of the commercially available Hoechst 33258) and in particular the three structural isomers designated ortho-, meta-, and para-iodo-Hoechst reflecting the position of the iodine substitution on the terminal ring. The ortho-analogue-subsequently referred to as $\mathrm{UV}_{\mathrm{A}} \mathrm{Sens}$ (Figure 1)-has shown remarkable photoefficiency, approximately 1000 -fold greater potency than that of the clinically used psoralens $[18,19]$. Upon $\mathrm{UV}_{\mathrm{A}}$ irradiation, $\mathrm{UV}_{\mathrm{A}}$ Sens is rapidly dehalogenated to phenyl Hoechst, creating a carbon-centered radical which is analogous to the uracilyl radical produced from the halogenated DNA precursors [17].

Recently, histone deacetylase inhibitors (HDACi) have evoked significant amounts of attention as a new class of antineoplastic agents, capable of inducing growth arrest, differentiation, and/or apoptosis of transformed cells [20]. In 2006, the HDACi suberoylanilide hydroxamic acid (SAHA, Vorinostat) (Figure 2(a)) became the first HDACi to be approved by the US Food and Drug Administration (FDA). SAHA is a broad-spectrum HDACi that at nanomolar concentrations is capable of inhibiting HDAC activity. Crystallographic studies have demonstrated that the mechanism of SAHA involves its binding to active sites of the HDACwhereby the hydroxamic end of the molecule binds to the zinc atom in the HDAC catalytic site, with the phenyl ring of SAHA projecting out of the catalytic pocket on to the surface of the HDAC [20]. Specifically, this drug is for the treatment of progressive, persistent or recurrent CTCL, after which two systemic therapies have failed $[21,22]$. The cyclic tetrapeptide depsipeptide (romidepsin) has also been approved for the treatment of CTCL [23]. In addition to their autonomous antitumour capacity, HDACi have shown to be synergistic with a number of commonly used anticancer agents, further signifying their potential as therapeutic agents [24]. Considering the already established therapeutic benefits of treatment of CTCL with both HDACi and phototherapy illuminates the imminent possibility of combination therapy, and further the opportunity to identify potential synergistic or additive activities. Here we investigated the application of combination therapy-specifically using SAHA and $\mathrm{UV}_{\mathrm{A}} \mathrm{Sens} / \mathrm{UV}_{\mathrm{A}}$-in four haematological cell lines. We utilised $\gamma \mathrm{H} 2 \mathrm{AX}$, a highly specific and sensitive molecular 


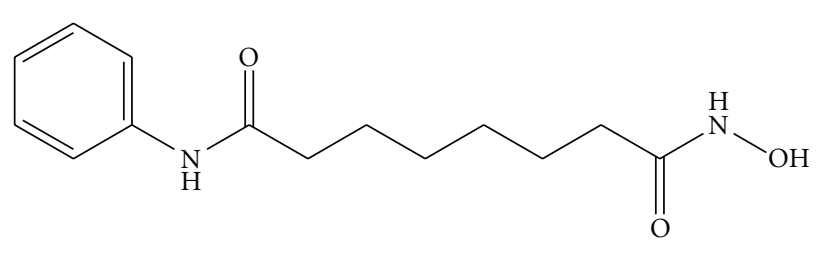

(a)

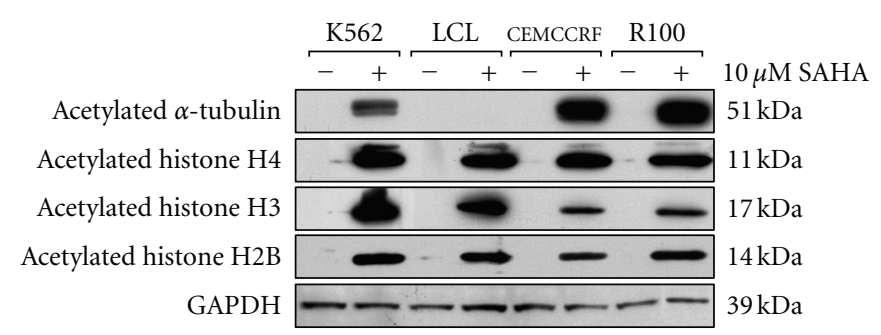

(b)

FIGURE 2: SAHA induces the accumulation of hyperacetylated histone and nonhistone protein in malignant and transformed haematological cells. Chemical structure of SAHA (a). Effects of SAHA on histone H2B, H3, and H4 acetylation, as well as $\alpha$-tubulin acetylation in haematological K562, CEM-CCRF, R100, and LCL cells. Cells were pretreated with $10 \mu \mathrm{M}$ of SAHA for 24 hours prior to extraction of whole cell lysates. Immunoblots of specific antibodies to acetylated histones $\mathrm{H} 2 \mathrm{~B}, \mathrm{H} 3, \mathrm{H} 4$, and $\alpha$-tubulin are shown. Equal loading and transfer were verified by probing the membranes with GAPDH (b).

marker of DNA double-strand breaks, to explore the combinatorial effects of HDAC inhibition and phototherapy.

\section{Materials and Methods}

2.1. Routine Cell Culture and $U V_{A}$ Irradiation. Human chronic myelogenous leukemia K562 cells [25] and the lymphoblastoid cell line (LCL) were maintained in completeRoyal Park Memorial Institute (RPMI) 1640 medium supplemented with $20 \mathrm{mmol} / \mathrm{L}$ HEPES (pH 7.4), 10\% (v/v) fetal bovine serum (FBS), $2 \mathrm{mmol} /$ glutamine, and 80 gentamicin units (GIBCO-Invitrogen). CEM-CCRF cells were maintained in $\alpha$ Modified Eagle's Medium ( $\alpha$-MEM) supplemented with $2 \mathrm{mmol} / \mathrm{L}$ HEPES (pH 7.4), 10\% (v/v) FBS, $2 \mathrm{mmol} /$ glutamine, and 80 units gentamicin. Similarly, Pglycoprotein (PGP) overexpressing, R100 cells [26], were grown in a-MEM supplemented with $2 \mathrm{mmol} / \mathrm{L}$ HEPES ( $\mathrm{pH} 7.4), 10 \%(\mathrm{v} / \mathrm{v})$ FBS, $2 \mathrm{mmol} /$ glutamine, 80 gentamicin units and $100 \mathrm{ng} / \mathrm{mL}$ vinblastine. R100 cells were cultured in $\alpha$-MEM/FBS/gentamicin media without vinblastine for 7 days prior to use in experiments. All cells were cultured in suspension in a humidified atmosphere of $5 \%(\mathrm{v} / \mathrm{v}) \mathrm{CO}_{2}$ at $37^{\circ} \mathrm{C}$ and were maintained in exponential growth phase.

For $\mathrm{UV}_{\mathrm{A}}$ radiation, $\mathrm{UV}$ dosimetry was employed to determine the amount of time required to achieve varying doses of $U_{\mathrm{A}}$ (fluence) at a certain flux (dose rate). Cells were irradiated with relevant fluencies $\left(50 \mathrm{~J} / \mathrm{m}^{2}\right)$ of $\mathrm{UV}_{\mathrm{A}}$ (8 Watt, black light fluorescent lamps: UVP, Upland, CA, USA), and the flux (UVX radiometer, measuring $365 \mathrm{~nm}$, UVP) was adjusted such that irradiations were completed within 2 minutes.

2.2. Preparation of Ortho-Iodo-Hoechst. Synthesis of the bisbenzimidazole analogue ortho-iodoHoechst was performed by Associate Professor Jonathan White (The School of Chemistry, The University of Melbourne) as previously described [27]. The Hoechst analogue was stored as lyophilised pellets in the dark. Concentrated stock solutions were prepared in $45 \%(\mathrm{v} / \mathrm{v})$ ethanol/sterile $\mathrm{dH}_{2} \mathrm{O}$ and further dilutions were prepared in $\mathrm{dH}_{2} \mathrm{O}$.
2.3. Drug Treatments. For experiments which required pretreatment with SAHA, 24 hours prior to initiation of experiment, 5 or $10 \mu \mathrm{M}$ SAHA (Sigma-Aldrich) were prepared via dilutions of stock solutions in PBS without $\mathrm{Ca}^{2+}$ and $\mathrm{Mg}^{2+}$ $(\mathrm{PBS}(-))$. SAHA was stored as a concentrated stock $(10 \mathrm{mM})$ at $-20^{\circ} \mathrm{C}$. Following 24 hours incubation with SAHA in a humidified environment $\left(37^{\circ} \mathrm{C}, 5 \% \mathrm{CO}_{2}\right)$, cells were treated with 0.1 or $5 \mu \mathrm{M}$ ortho-iodo Hoechst 33258 and incubated at $37^{\circ} \mathrm{C}, 5 \% \mathrm{CO}_{2}$ for 1 hour prior to irradiation with $50 \mathrm{~J} / \mathrm{m}^{2}$ intensity of $\mathrm{UV}_{\mathrm{A}}$ radiation. Postirradiation cells were incubated for a further hour at $37^{\circ} \mathrm{C}, 5 \% \mathrm{CO}_{2}$. Subsequently cells were either examined for $\gamma \mathrm{H} 2 \mathrm{AX}$ immunofluorescence assays, apoptosis, cell viability, or western blot using methods described below.

2.4. $\gamma H 2 A X$ Immunofluorescence. Following varying treatments, each of the 4 cell lines were fixed and stained for $\gamma \mathrm{H} 2 \mathrm{AX}$ foci, as described previously $[28,29]$. Images were acquired using a Zeiss 510 Meta Confocal Microscope using a step size of $0.5 \mu \mathrm{m}$ to obtain optical $\mathrm{z}$ slices. Images of cells were then stacked and merged using Metamorph software (Molecular Probes, Oregon, USA) to obtain a 2D image for immunofluorescence visualisation of $\gamma \mathrm{H} 2 \mathrm{AX}$ foci (green) and the nucleus (TO-PRO3, blue). The average number of $\gamma \mathrm{H} 2 \mathrm{AX}$ foci per nucleus was quantified using Image J analysis software Fiji Version 1.44a).

2.5. Immunoblotting. Histone hyperacetylation was assessed by immunoblotting of total cell protein extracted following treatment for 24 hours with $10 \mu \mathrm{M}$ SAHA. Cells were pelleted at 1200 revolutions per minute (RPM) for 5 minutes and washed twice in ice-cold PBS, with subsequent procedures all performed on ice. Cell pellets were resuspended in mammalian protein extraction reagent (M-PER) (M-PER; Thermo Scientific, Rockford, USA) at a ratio of $60 \mu \mathrm{L} \mathrm{M-}$ PER reagent to $1 \times 10^{6}$ cells. The cell suspension was lysed via agitation for 10 minutes at $4^{\circ} \mathrm{C}$, and supernatant was collected following centrifugation at $14,000 \mathrm{~g}$ for 15 minutes at $4^{\circ} \mathrm{C}$. The protein content was measured using the bradford protein assay with bovine serum albumin standards (BSA, Sigma-Aldrich) at $595 \mathrm{nM}$ using a Emax Precision 
microplate reader. Equal amounts of protein $(40 \mu \mathrm{g} / \mathrm{lane})$ were separated using NuPAGE 4-12\% gels (Invitrogen) and transferred to nitrocellulose membranes. SeaBlue Plus 2 (Invitrogen) prestained molecular weight size standards were used. Membranes were incubated for 1 hour in 5\% skim milk $((\mathrm{w} / \mathrm{v})$ in PBS-T) $(0.05 \%$ Tween $20, \mathrm{PBS}(-))$, briefly rinsed in PBS-T and incubated overnight with primary antibodies: monoclonal rabbit antiacetylated histone H2B $(1: 200000$, Epitomics), polyclonal rabbit anti-acetylated histone $\mathrm{H} 3$ (1:2000, Millipore), polyclonal rabbit anti-acetylated histone H4 (1:2000, Millipore) or monoclonal mouse antiacetylated $\alpha$-tubulin. Following this, membranes were incubated for an additional hour with corresponding peroxidase labelled secondary antibody (Millipore, Billerica, MA). After incubation, immunoreactive bands were visualised using chemiluminescent reagent (ECL) (GE Healthcare, Chalfont St. Giles, Buckinghamshire, UK) according to the manufacturer's instructions. Equal loading and transfer were verified by probing the membranes with GAPDH.

2.6. Drug Uptake Studies. Uptake of $\mathrm{UV}_{\mathrm{A}}$ Sens in K562, LCL, CEM-CCRF, and R100 cells was examined to determine whether differences in DNA damage were due to differences in uptake of SAHA. Cells were seeded at a density of $10^{6}$ cells per $\mathrm{mL}$ in 96 well black plates and incubated with $10 \mu \mathrm{M}$ SAHA for 24 hours at $37^{\circ} \mathrm{C}, 5 \% \mathrm{CO}_{2}(\mathrm{v} / \mathrm{v})$ prior to a 2 hour incubation with $5 \mu \mathrm{M} \mathrm{UV}_{\mathrm{A}}$ Sens. Final volumes were made to $200 \mu \mathrm{L}$. After incubations, $20 \mu \mathrm{L}$ cell droplets were dried on slides and rehydrated with $\mathrm{PBS}(-)$ immediately prior to imaging on a BX61 upright fluorescence microscope with a 20x UplanFL air Ph1, 0.5 NA objective, and DAPI lens (Olympus, Tokyo, Japan).

2.7. Cell Viability and Apoptosis. Cells were treated with 0 , 2 , 5, or $10 \mu \mathrm{M}$ SAHA for 24 hours at $37^{\circ} \mathrm{C}, 5 \% \mathrm{CO}_{2}$ and measured for cell viability and caspase $3 / 7$ activity using the CellTiter-Blue and Apo-One homogeneous Caspase 3/7 kits, respectively, according to the manufacturer's instructions (Promega, Madison, WI, US). Fluorescence was measured using a Victor 3 (PerkinElmer, Waltham MA, USA) microplate reader.

2.8. Statistical Analysis. Statistical analysis was measured using Prism (version 5, GraphPad Software, San Diego, CA, USA). A one-way analysis of variance (ANOVA) was employed, with a Bonferroni posttest to determine the statistical significance between differing treatments. The level of significance was accepted at ${ }^{*} P<0.05,{ }^{* *} P<0.01$, and $* * * P<0.001$.

\section{Results}

3.1. SAHA Induces Accumulation of Hyperacetylated Histones. Western blot analysis was undertaken to investigate the acetylation status of histone and nonhistone protein of the four malignant cell lines following treatment with the HDAC inhibitor, SAHA (Figure 2(a)). Total cell lysates of K562, CEM-CCRF, R100, and LCL cells pretreated with or without
$10 \mu \mathrm{M}$ SAHA performed. Our findings showed that over 24 hours SAHA induces the accumulation of hyperacetylated histones- $-\mathrm{H} 2 \mathrm{~B}, \mathrm{H} 3$, and $\mathrm{H} 4$ in all four haematological cell lines (Figure 2(b)). In addition, the acetylation status of nonhistone cytoplasmic protein $-\alpha$-tubulin was also examined. We found $\alpha$-tubulin was hyperacetylated following SAHA treatment in all cell lines with the exception of the nonmalignant, transformed LCL cell (Figure 2(b)).

3.2. Effects of SAHA on Cell Viability and Apoptosis. Treatment with SAHA for both 24 and 48 hours decreases the relative cell viability of K562, CEM-CCRF, R100, and LCL cells (Figures 3(a), 3(c), 3(e), and 3(g), resp.). The greatest reduction in relative cell viability was seen in CEM-CCRF cells. HDAC inhibitor-mediated cell death often involves caspase activity. Caspase 3 and 7 activity was therefore monitored to observe the effect of SAHA on apoptosis. SAHA induced apoptosis in each of the four cell lines (Figures 3(b), $3(\mathrm{~d}), 3(\mathrm{f})$, and $3(\mathrm{~h}))$.

3.3. SAHA Increases Uptake of $U V_{A}$ Sens in Cell Nuclei. The uptake of $U_{A}$ Sens following treatment with SAHA was examined in all four heamatological cell lines. Analysis of the uptake by fluorescence intensity in K562, CEM-CCRF, R100, and LCL cells was undertaken after pretreatment for 24 hours with $10 \mu \mathrm{M}$ SAHA. Results revealed that when cells were treated with both HDACi and $\mathrm{UV}_{\mathrm{A}}$ Sens, there was an increase in fluorescence intensity in all cell lines, alluding to possible chromatin remodelling caused by the inhibition of histone deacetylases (Figure 4). Specifically in the case of the R100 cells, the uptake of $1 \mu \mathrm{M} \mathrm{UV}_{\mathrm{A}}$ Sens is considerably lower in comparison to the other haematological cell lines. The differences can be attributed to the expression of Pglycoprotein transporter, which effluxes drug out of the cell. With the addition of $10 \mu \mathrm{M}$ SAHA, the uptake of $\mathrm{UV}_{\mathrm{A}}$ Sens was significantly increased. Similarly, and to a greater extent, $5 \mu \mathrm{m} \mathrm{UV} \mathrm{A}_{\mathrm{A}}$ Sens causes a significant increase in mean fluorescent intensity, and this is only enhanced following pretreatment with SAHA in K562 and CEM-CCRF cells but not R100 or LCL cells.

3.4. Initial DNA Damage in Haematological Cell Lines. To compare initial DNA damage in the 4 cell lines: K562, CEMCCRF, R100, and LCL cells, a $\gamma \mathrm{H} 2 \mathrm{AX}$ immunofluorescence assay was performed on cells treated with $0.1 \mu \mathrm{M} \mathrm{UV}_{\mathrm{A}}$ Sens and $50 \mathrm{~J} / \mathrm{m}^{2}$ with and without $10 \mu \mathrm{M}$ SAHA. UV $\mathrm{U}_{\mathrm{A}}$ Sens $/ \mathrm{UV}_{\mathrm{A}}$ had a remarkable effect-significantly increasing both mean $\gamma \mathrm{H} 2 \mathrm{AX}$ foci and mean fluorescence intensity as compared to untreated cells $(P<0.001)$ in all four heamatological cell lines-K562 (Figure 5), CEM-CCRF (Figure 6), R100 (Figure 7), and LCL (Figure 8). Combination therapy with $10 \mu \mathrm{M}$ SAHA enhanced this cytotoxicity, leading to increased $\gamma \mathrm{H} 2 \mathrm{AX}$ foci and total nuclear fluorescence in all cell lines also. CEM-CCRF (Figure 6) and K562 cells (Figure 5), respectively, were found to have the greatest accumulation of $\gamma \mathrm{H} 2 \mathrm{AX}$ foci and mean fluorescence of cells with $\mathrm{UV}_{\mathrm{A}}$ Sens $/ \mathrm{UV}_{\mathrm{A}}$ treatment either alone or in combination with SAHA. R100 cell given it expresses P-glycoprotein and 


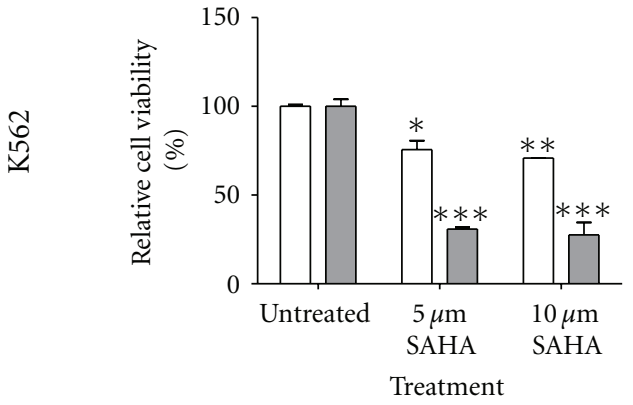

(a)

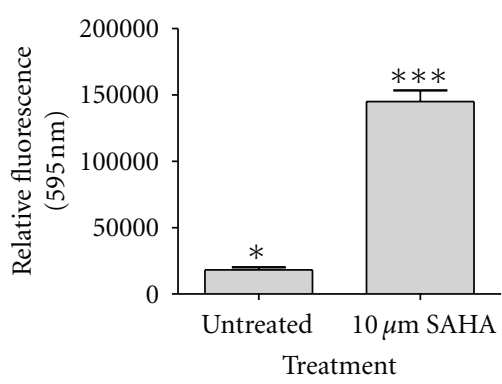

(b)

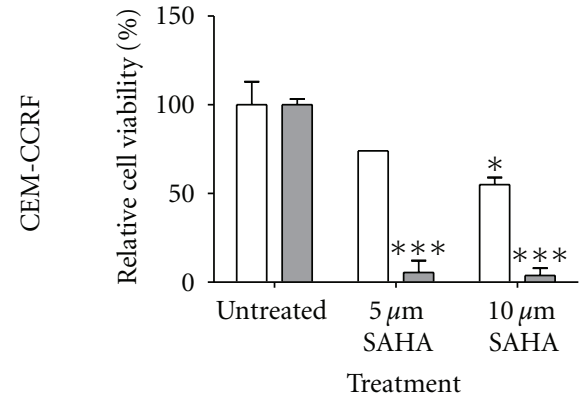

(c)

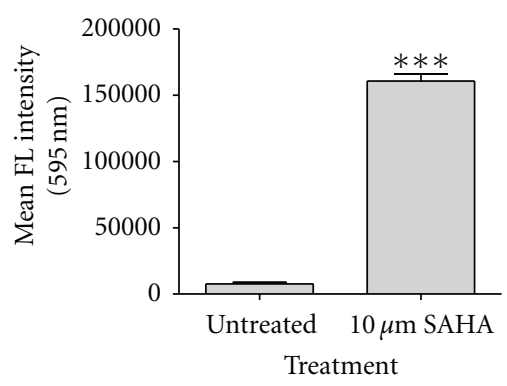

(f)

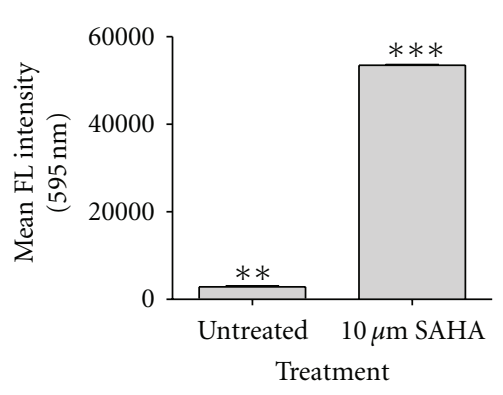

(d)

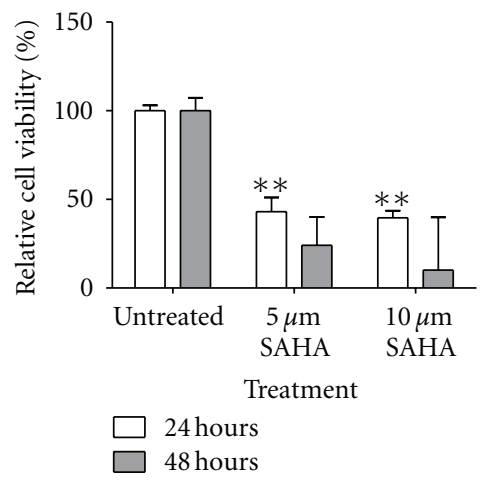

(g)

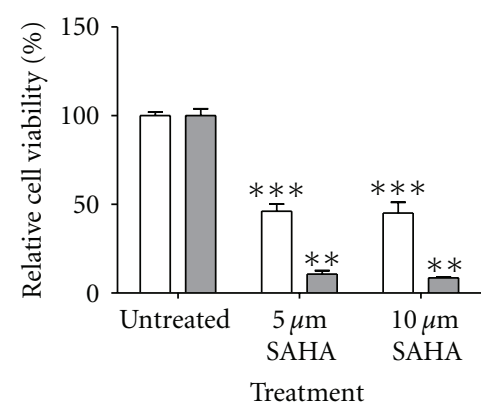

(e)

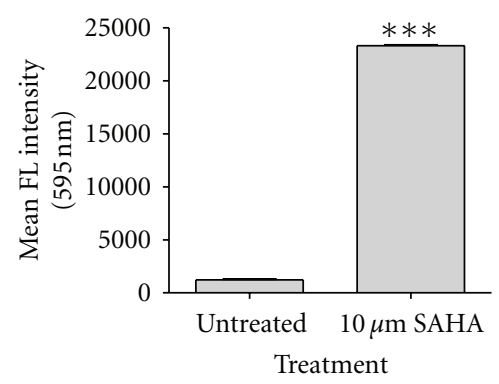

(h)

FIGURE 3: SAHA decreases the viability and increases apoptosis in malignant and transformed haematological cells. K562 (a), CEM-CCRF (c), R100 (e), and LCL (g) cells were treated with the indicated concentration of SAHA for 24 and 48 hours, and the cell viability was measured using the CellTiter-Glo Luminescent Cell Viability Assay kit. The data is presented as the percentage of growth inhibition relative to untreated cells. For the measurement of apoptosis, 48 hours after incubation with HDACi, the level of caspase 3/7 activity was analysed in K562 (b), CEM-CCRF (d), R100 (f), and LCL (h) cells using the Caspase-Glo 3/7 assay kit following manufacturer instructions. Results are expressed as means $\pm \mathrm{SEM}, n=2 .{ }^{*} P<0.05,{ }^{* *} P<0.01,{ }^{* * *} P<0.001$ as compared to untreated.

transformed LCL cells has significantly lower accumulation of $\gamma \mathrm{H} 2 \mathrm{AX}$ foci in comparison to CEMCCRF cells and K562 cells which suggests the necessity of using combinational therapeutics to increase damage in these cell lines.

\section{Discussion}

To first evaluate the effects of SAHA alone, primary experiments aimed specifically towards exploring its properties were undertaken. Immunoblot analysis performed on each of the 4 cell lines pre-treated with the broad-spectrum HDACi SAHA demonstrated that as expected, the HDACi induces hyperacetylation of both histone and nonhistone proteins (Figure 2(b)). Histone acetylation is an important regulatory mechanism opening up the chromatin structure and so altering the accessibility of transcription factors to DNA. This in turn modulates gene expression [30]. Previously, using MNase digestion assays, we have identified the ability of Trichostatin A, like SAHA a hydroxamic acid and broad-spectrum HDACi, to open the chromatin structure in K562 cells [31]. With this in mind, uptake studies of $\mathrm{UV}_{\mathrm{A}}$ Sens were initiated. The intrinsic fluorescence properties of the bibenzidazimazole, which are enhanced upon binding to DNA, provide an optimal opportunity to further study HDACi. Given that pre-treatment with SAHA results in a 


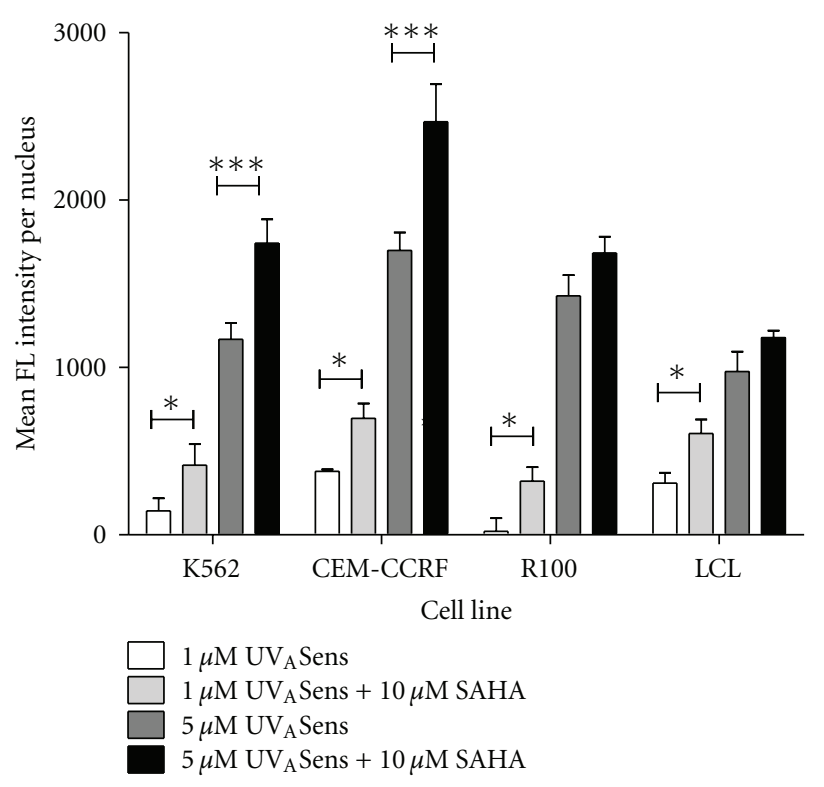

FIgURE 4: SAHA increases the uptake of $\mathrm{UV}_{\mathrm{A}}$ Sens in malignant and transformed haematological cells. K562, CEM-CCRF, R100, and LCL cells were pretreated with $10 \mu \mathrm{M}$ of SAHA for 24 hours prior to 2 hour incubation with either 1 or $5 \mu \mathrm{M} \mathrm{UV} \mathrm{UV}_{\mathrm{A}}$ Sens, and the uptake of drug was measured by the fluorescence intensity levels. Given R100 express the P-glycoprotein transporter, uptake of $1 \mu \mathrm{M}$ of $\mathrm{UV}_{\mathrm{A}}$ Sens is lower compared to the other cell lines but increases with the addition of $10 \mu \mathrm{M}$ SAHA as shown in all cell lines. Result are expressed as means $\pm \mathrm{SD}, n=2 .{ }^{*} P<0.05,{ }^{* * *} P<0.001$.

more open chromatin conformation, it was hypothesised that there would be increased levels of fluorescence with combination treatment of cells (both SAHA and $\mathrm{UV}_{\mathrm{A}}$ Sens) as compared to $\mathrm{UV}_{\mathrm{A}}$ Sens alone. While the mechanisms through which SAHA exerts these actions have not been fully delineated, increased number of binding sites available, an increase in the number of susceptible sites for radial attack, or possibly as a result of a reduction in the scavenging capacity of the chromatin are possible reasons functions of the HDACi. This concept of chromatin remodelling was explored in each of the 4 cell lines. Results revealed that total nuclear fluorescence was increased in all cell types tested when cells were pre-treated with SAHA (Figure 4). Hence this highlights the ability of SAHA to open the chromatin conformation, subsequently allowing $\mathrm{UV}_{\mathrm{A}}$ radiation to cause increased numbers of double-strand breaks, possibly via indirect DNA damage by free radicals [32]. Therefore, we have identified a potentiating effect of SAHA on $\mathrm{UV}_{\mathrm{A}} \mathrm{Sens} / \mathrm{UV}_{\mathrm{A}}$-induced cell damage.

In addition HDACi target histone and non-histone proteins which regulate gene expression, cell cycle progression, and cell death [33]. They are therefore well accepted to induce apoptosis and subsequently reduce cell viability [34], and so the effect of SAHA on cell viability and induction of apoptosis was assessed using the CellTiter-Blue and Apo-One Homogeneous Caspase 3/7 assay kits, respectively. Indeed, treatment of each of the 4 cell lines with SAHA resulted in a disruption of the proliferative nature of the haematological cell lines. This was observed from cell viability data which indicated that for all of the 4 cell lines, incubation with SAHA for 24 and 48 hours significantly reduced cell viability in a time-dependent manner (Figure 3). Further, HDACi have been shown to induce caspase-independent autophagic cell death and apoptosis by mitochondria/cytochrome $c$ mediated caspase activation pathways [35]. Analysis of caspase $3 / 7$ activation in the 4 cell lines provided complementary results to those found for cell viability analysis. SAHA causes significant apoptosis in all cell lines, a finding that is complementary to other studies that have demonstrated SAHA's ability to mediate apoptosis via novel mechanisms involving activation of the intrinsic death pathway resulting in caspase-dependent cell death [36, 37].

In line with findings of recent studies demonstrating the efficiency of using the HDACi sodium butyrate and TSA together with PUVA therapy in various cell lines [38] and extending on previous studies conducted in this laboratory using $\mathrm{UV}_{\mathrm{A}}$ Sens and TSA [39], the concept of using combination treatment involving the Hoechst analogue for the treatment of CTCL was further explored. With the effect of HDACi well established, damage in the form of double-strand breaks from $\mathrm{UV}_{\mathrm{A}}$ radiation was analysed with $\gamma \mathrm{H} 2 \mathrm{AX}$ immunofluorescence assays. DNA double-strand breaks (DSB) constitute one of the most severe forms of DNA damage, having severe consequences on cell survival and maintenance of genomic stability [40-42]. While they result as by-products of endogenous processes, they are also formed as a consequence of a variety of exogenous insults including ionising radiation (X-rays and $\gamma$-rays), ultraviolet rays, oxidative stress, and some chemical agents [43]. Upon induction of a DSB, phosphorylation of the histone variant $\mathrm{H} 2 \mathrm{AX}$ on the Ser-139 residue occurs, resulting in discrete foci at the site of damage. Consequently $\gamma \mathrm{H} 2 \mathrm{AX}$ formation is a rapid and sensitive cellular marker to the presence of DNA DSB [44]. Using this model, we were able to identify the relative potency of the ortho-isomer of Hoechst $33258, \mathrm{UV}_{\mathrm{A}}$ Sens, upon exposure to $\mathrm{UV}_{\mathrm{A}}$ radiation both as a standalone treatment, and in combination with SAHA-possibly alluding to an additive, or even synergistic therapeutic potential.

Experiments were undertaken in parallel involving four cell lines to examine the effects of $\mathrm{UV}_{\mathrm{A}} \mathrm{Sens} / \mathrm{UV}_{\mathrm{A}}$ and HDACi. This allowed for a direct contrast to be made on the effect of the Hoechst analogue in varying cell lines. Combination treatment with SAHA augmented cytotoxicity in all four of the cell lines. A common occurrence in cancer therapy is the development of resistance to drug treatment [45]. Malignant cells frequently have a poor response to antitumour drugs on account of the development of the multidrug resistance (MDR) phenotype [46]. One mechanism of resistance is increased expression of the ATP-dependent efflux pump, the membrane P-glycoprotein (PGP) pump, from the ATP-binding cassette (ABC) transporter family [47]. This pump, encoded by the human multidrug resistance gene 1 (MDR1) gene, causes efflux of drugs from the cell, and hence induces MDR [26]. It has been shown that suppression of this PGP-pump in certain cancer patients with the PGP inhibitor-cyclosporine A—significantly improved remission and survival rates [48]. 


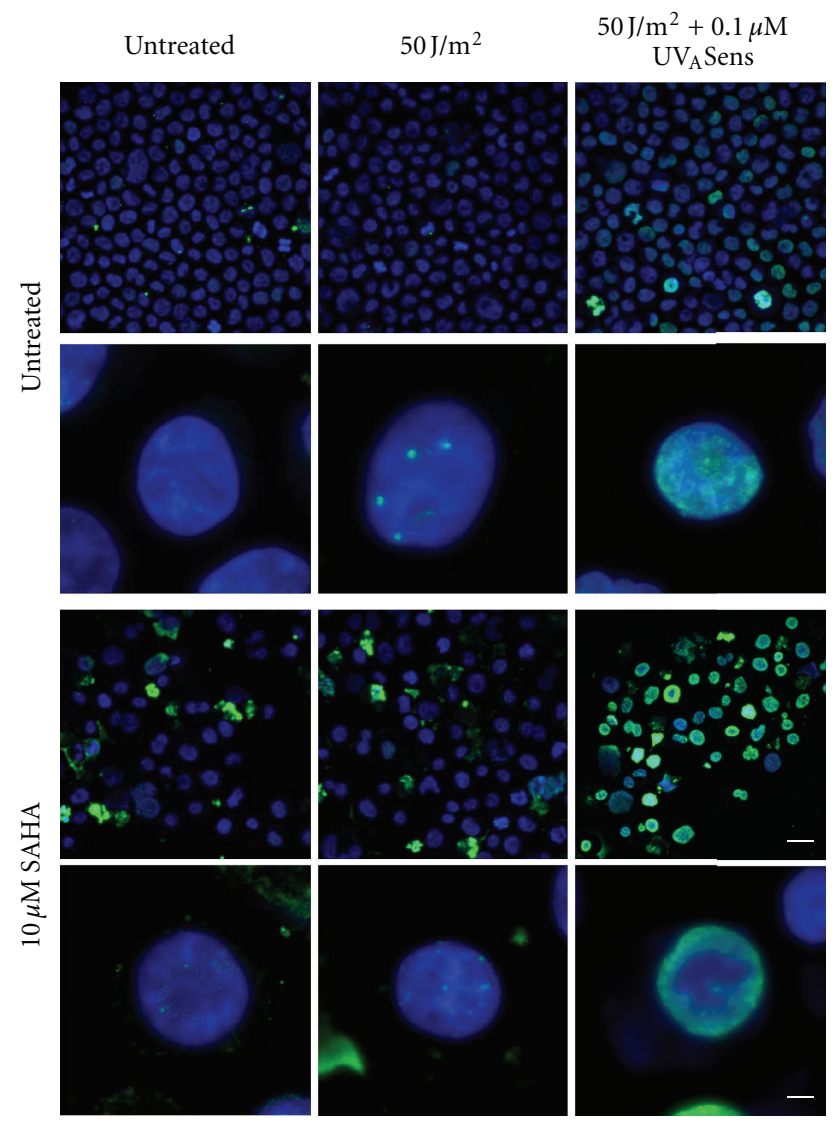

(a)

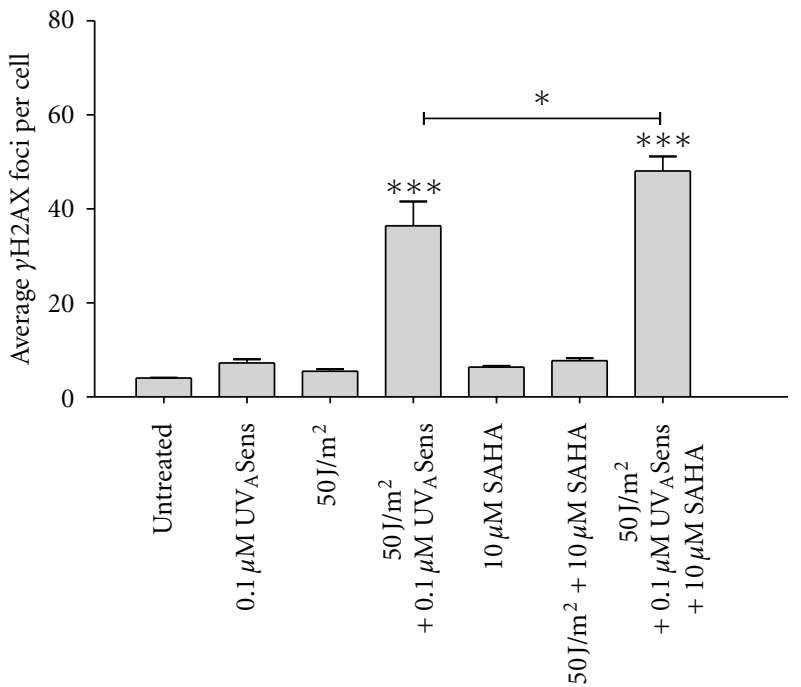

Treatment

(b)

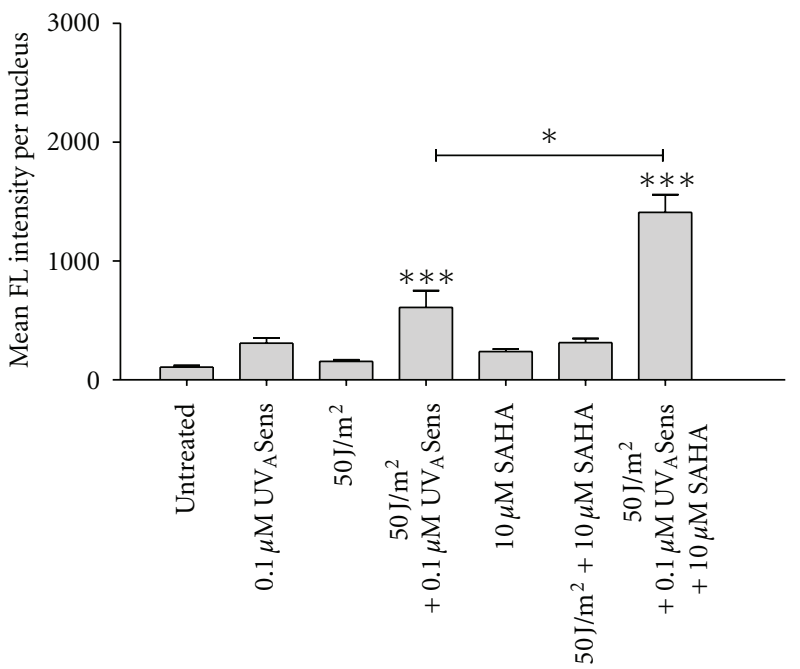

Treatment

(c)

FIGURE 5: HDACi enhance $\mathrm{UV}_{\mathrm{A}}$ Sens/UV $\mathrm{U}_{\mathrm{A}}$-induced accumulation of $\gamma \mathrm{H} 2 \mathrm{AX}$ fluorescence in K562 cells. Cells were pretreated with $10 \mu \mathrm{M}$ SAHA for 24 hours prior to a 1-hour treatment with $0.1 \mu \mathrm{M} \mathrm{UV} \mathrm{A}_{\mathrm{A}}$ Sens and $\mathrm{UV}_{\mathrm{A}}$ radiation of cells with $50 \mathrm{~J} / \mathrm{m}^{2}$. One hour after irradiation, cells were fixed and stained for $\gamma \mathrm{H} 2 \mathrm{AX}$, following which images were acquired using a Zeiss 510 Meta Confocal Microscope using $0.5 \mu \mathrm{m}$ $\mathrm{z}$-sectioning (a). Images were stacked and merged using Metamorph software for immunofluorescence visualisation of $\gamma \mathrm{H} 2 \mathrm{AX}$ fluorescence (green) in nuclei (TO-PRO-3, blue). Total nuclear fluorescence was measured (b) using Image J analysis software. Mean \pm standard deviations from a single experiment performed in duplicate are shown. Bar $=20 \mu \mathrm{m}$; 63x magnification. ${ }^{*} P<0.05, * * * P<0.001$ compared to untreated cells. 


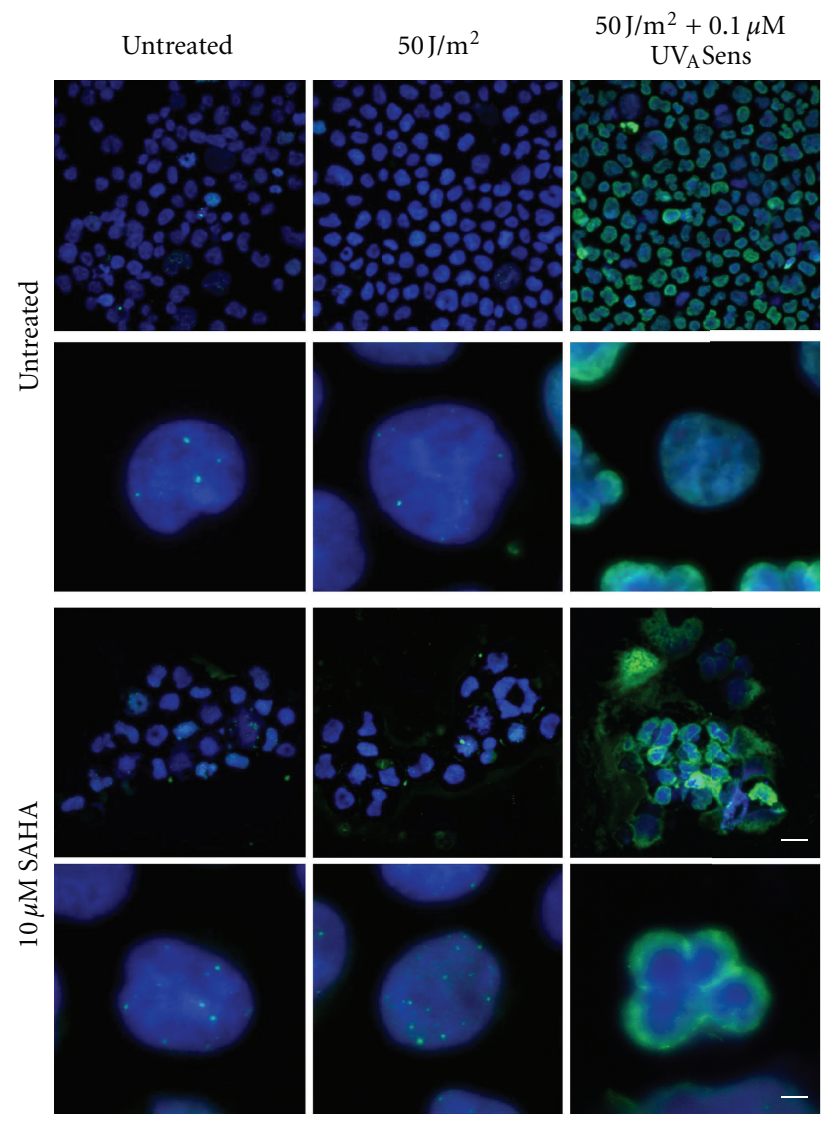

(a)

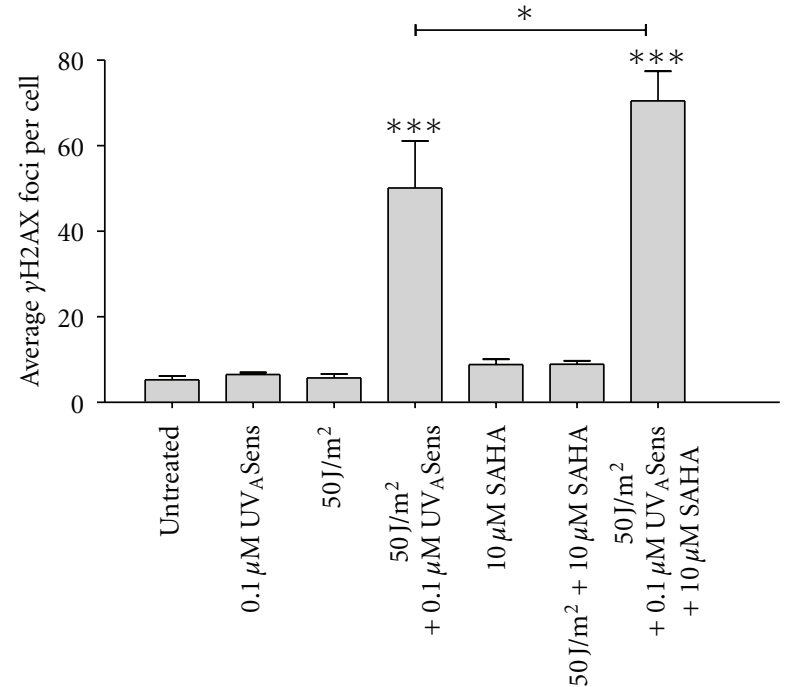

Treatment

(b)

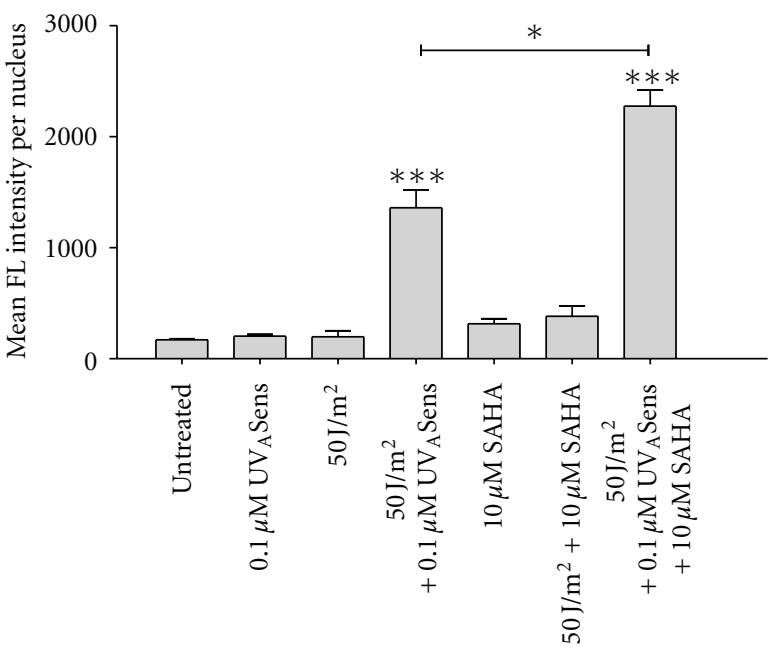

Treatment

(c)

FIGURE 6: HDACi enhance $\mathrm{UV}_{\mathrm{A}}$ Sens/UV $\mathrm{UV}_{\mathrm{A}}$-induced accumulation of $\gamma \mathrm{H} 2 \mathrm{AX}$ fluorescence in CEM-CCRF cells. Cells were pretreated with $10 \mu \mathrm{M}$ SAHA for 24 hours prior to a 1-hour treatment with $0.1 \mu \mathrm{M} \mathrm{UV}$ Sens and $\mathrm{UV}_{\mathrm{A}}$ radiation of cells with $50 \mathrm{~J} / \mathrm{m}^{2}$. One hour after irradiation, cells were fixed and stained for $\gamma \mathrm{H} 2 \mathrm{AX}$, following which images were acquired using a Zeiss 510 Meta Confocal Microscope using $0.5 \mu \mathrm{m}$ z-sectioning (a). Images were stacked and merged using Metamorph software for immunofluorescence visualisation of $\gamma \mathrm{H} 2 \mathrm{AX}$ fluorescence (green) in nuclei (TO-PRO-3, blue). Total nuclear fluorescence was measured (b) using Image J analysis software. Mean \pm standard deviations from a single experiment performed in duplicate are shown. Bar $=20 \mu \mathrm{m} ; 63 \mathrm{x}$ magnification. ${ }^{*} P<0.05,{ }^{* * *} P<0.001$ compared to untreated cells. 


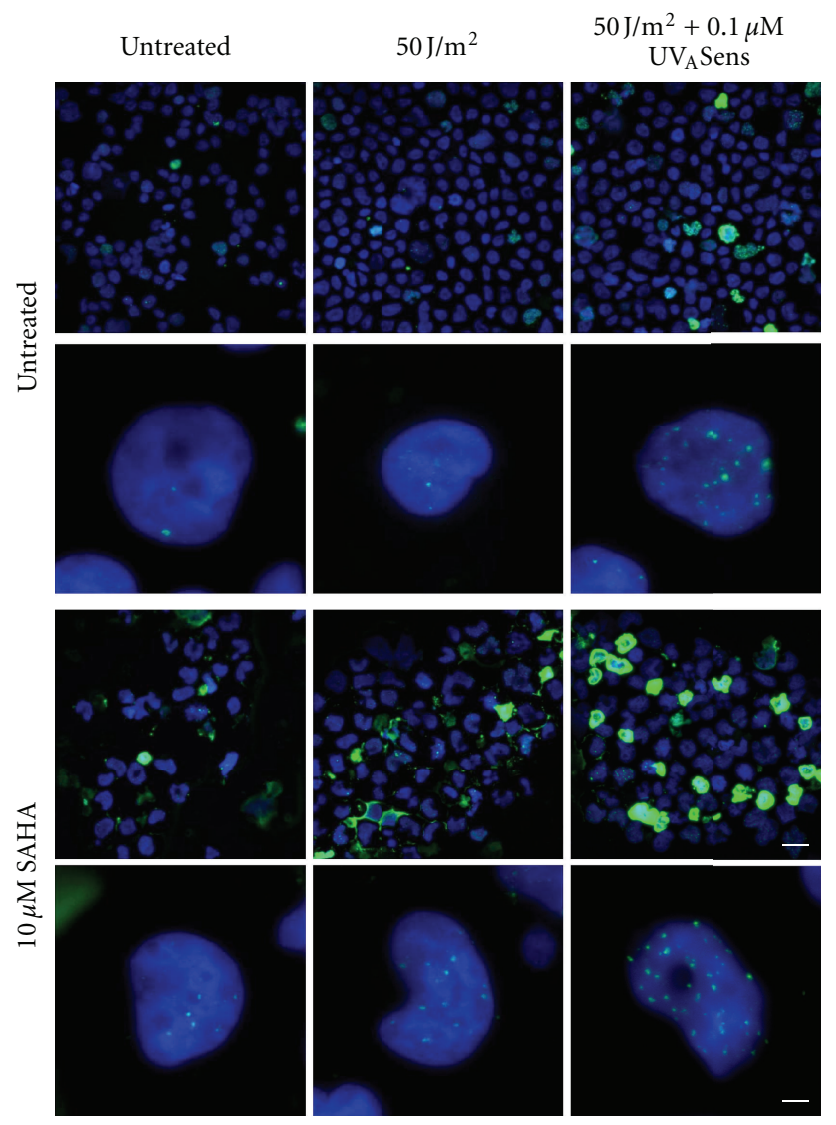

(a)

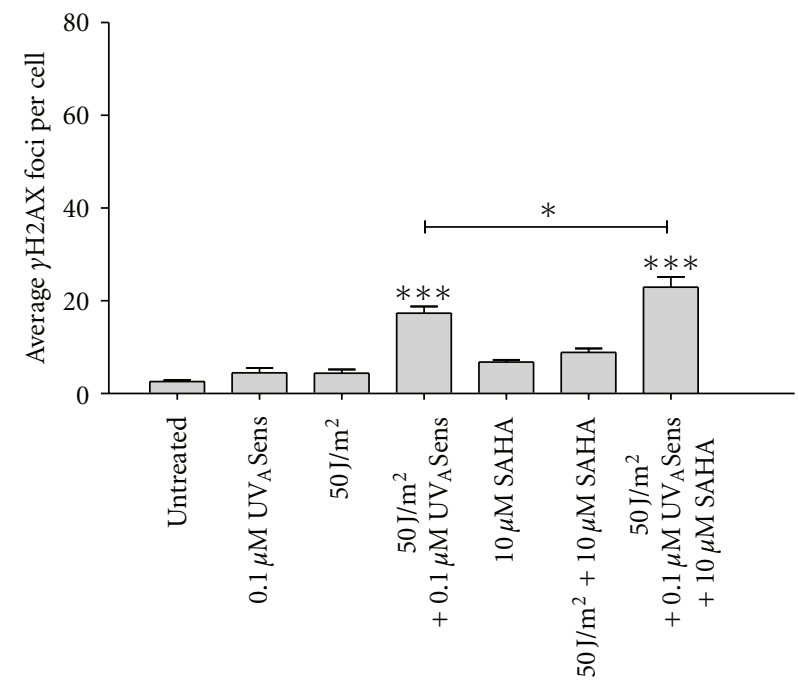

Treatment

(b)

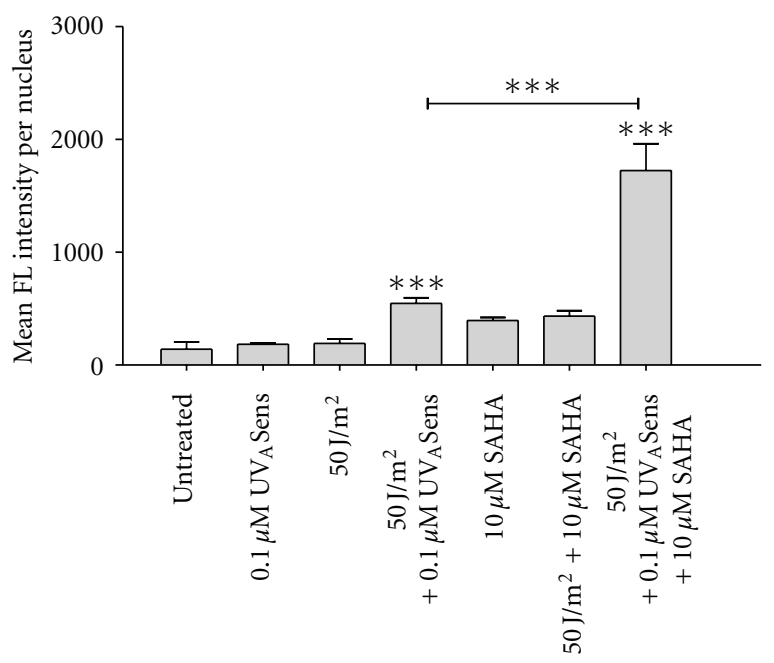

Treatment

(c)

Figure 7: HDACi enhance $\mathrm{UV}_{\mathrm{A}}$ Sens/UV $\mathrm{U}_{\mathrm{A}}$-induced accumulation of $\gamma \mathrm{H} 2 \mathrm{AX}$ foci in R100 cells. Cells were pretreated with $10 \mu \mathrm{M}$ SAHA for 24 hours prior to a 1-hour treatment with $0.1 \mu \mathrm{M} \mathrm{UV} \mathrm{U}_{\mathrm{A}}$ Sens and $\mathrm{UV}_{\mathrm{A}}$ radiation of cells with $50 \mathrm{~J} / \mathrm{m}^{2}$. One hour after irradiation, cells were fixed and stained for $\gamma \mathrm{H} 2 \mathrm{AX}$, following which images were acquired using a Zeiss 510 Meta Confocal Microscope using $0.5 \mu \mathrm{m}$ z-sectioning (a). Images were stacked and merged using Metamorph software for immunofluorescence visualisation of $\gamma \mathrm{H} 2 \mathrm{AX}$ foci (green) in nuclei (TO-PRO-3, blue). The average number of $\gamma \mathrm{H} 2 \mathrm{AX}$ foci was quantified (a), and total nuclear fluorescence was measured (c) using Image J analysis software. Mean \pm standard deviations from a single experiment performed in duplicate are shown. Bar $=20 \mu \mathrm{m} ; 63 \mathrm{x}$ magnification. ** $P<0.01,{ }^{* * *} P<0.001$ compared to untreated cells. 


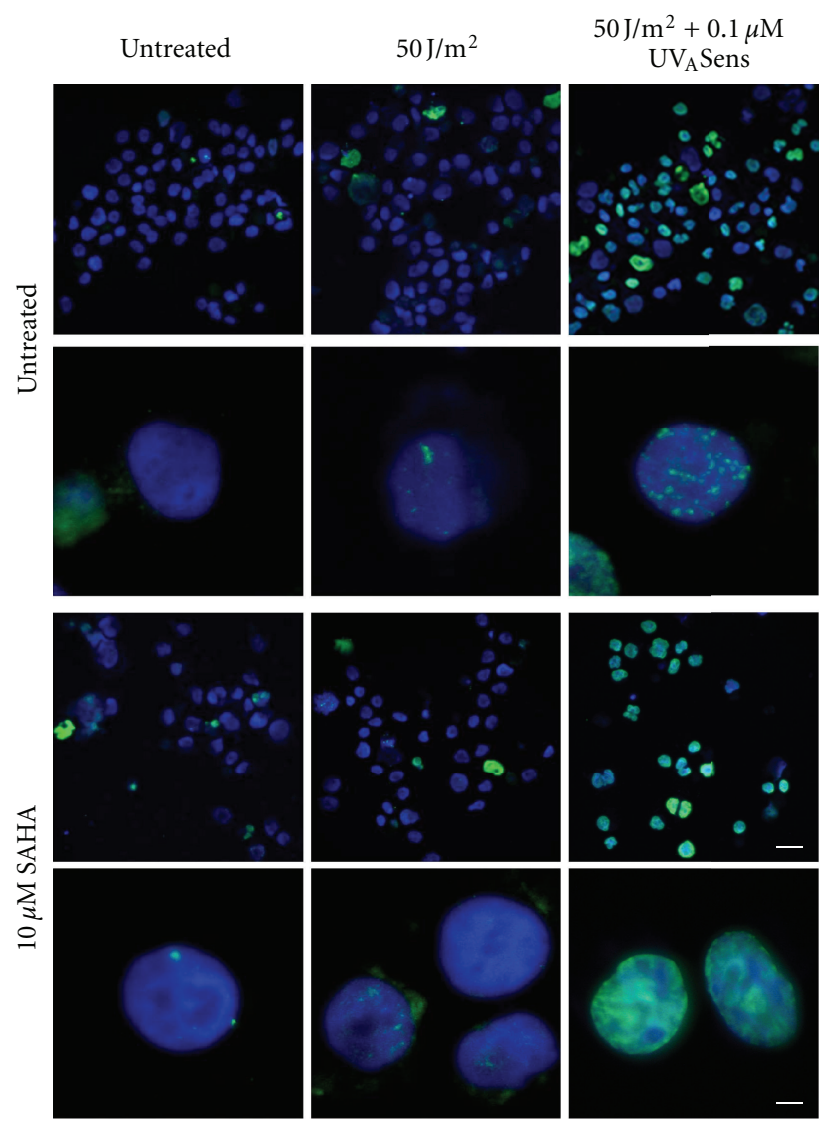

(a)

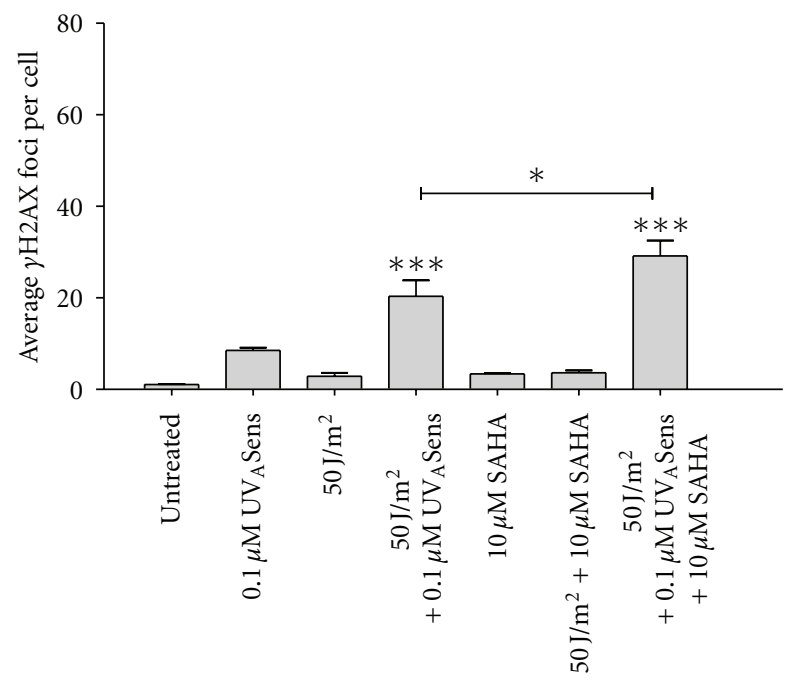

Treatment

(b)

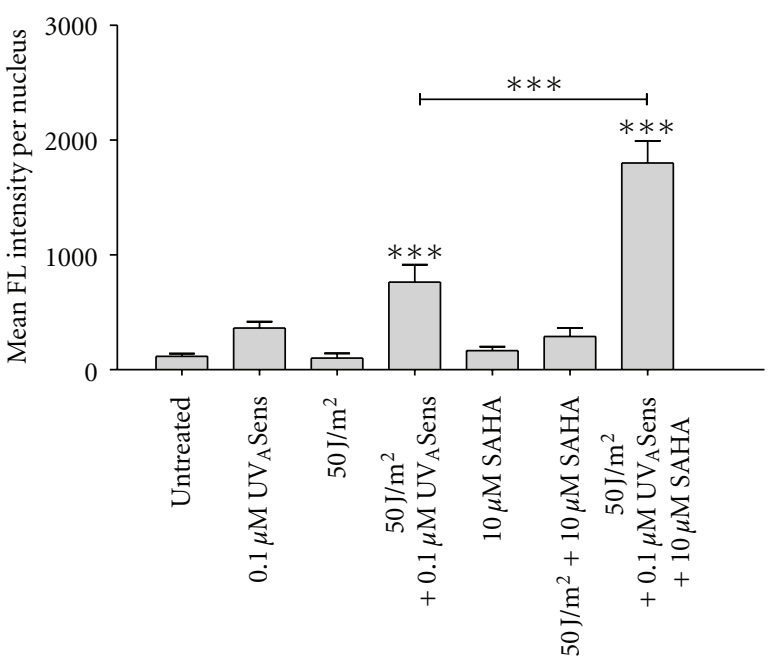

Treatment

(c)

FIgURE 8: HDACi enhance $\mathrm{UV}_{\mathrm{A}}$ Sens/ $\mathrm{UV}_{\mathrm{A}}$-induced accumulation of $\gamma \mathrm{H} 2 \mathrm{AX}$ foci in LCL cells. Cells were pretreated with $10 \mu \mathrm{M}$ SAHA for 24 hours prior to a 1-hour treatment with $0.1 \mu \mathrm{M} \mathrm{UV}$ Sens and $U_{\mathrm{A}}$ radiation of cells with $50 \mathrm{~J} / \mathrm{m}^{2}$. One hour after irradiation, cells were fixed and stained for $\gamma \mathrm{H} 2 \mathrm{AX}$, following which images were acquired using a Zeiss 510 Meta Confocal Microscope using $0.5 \mu \mathrm{m} z$-sectioning (a). Images were stacked and merged using Metamorph software for immunofluorescence visualisation of $\gamma \mathrm{H} 2 \mathrm{AX}$ foci (green) in nuclei (TO-PRO-3, blue). The average number of $\gamma \mathrm{H} 2 \mathrm{AX}$ foci was quantified (a), and total nuclear fluorescence was measured (c) using Image J analysis software. Mean \pm standard deviations from a single experiment performed in duplicate are shown. Bar $=20 \mu \mathrm{m} ; 63 \mathrm{x}$ magnification. $* * * P<0.001$ compared to untreated cells. 
Studies have shown R100 cells to have expression levels of mRNA for PGP approximately 50 times to that of its parental cell line-CEM-CCRF [26]. This prompted the speculation that there would be increased resistance noticed during experimental undertakings, this however was not the case. With the chromatin remodelling studies, while no significant increase in uptake was noticed following treatment with $1 \mu \mathrm{M} \mathrm{UV} \mathrm{A}_{\mathrm{A}}$ Sens, when these cells were pre-treated with $10 \mu \mathrm{M}$ SAHA, a significant increase in uptake was seen (Figure 4). This indicates that at low concentrations of $\mathrm{UV}_{\mathrm{A}}$ Sens, the presence of the PGP pump in the R100 cells leads to efflux of the drug therefore preventing it from binding the nucleus and so resulting in low levels of fluorescence. The increase in fluorescence noticed following the addition of the SAHA suggests an ability of the HDACi to alter the properties of the PGP pump, perhaps through altering the expression of certain genes, therefore allowing the bibenzimidalzole to bind to the cell nucleus, increasing the mean fluorescence intensity. At higher concentrations of $\mathrm{UV}_{\mathrm{A}}$ Sens, noticeably $5 \mu \mathrm{M}$, even in the absence of SAHA, a significant level of uptake of the drug was observed (Figure 4). Therefore, we can infer that the PGP pump is no longer able to efflux the drug-possibly due to the loss of function of the pump, or perhaps at these higher concentrations of $\mathrm{UV}_{\mathrm{A}}$ Sens, saturation of the binding sites has occurred, and so accounts for the higher levels of fluorescence. Nevertheless, the mechanisms of resistance of the R100 cell line are failing, and so levels measured are similar to that the parental cell line-CEM-CCRF. Further, in the apoptosis and cell viability studies it was found that posttreatment with SAHA an increase in apoptosis (Figure 3(f)) and decrease in viability (Figure 3(e)) of the cell resulted in all 4 of the haematological cells, including R100. This once again indicates that SAHA has an effect to inhibit the MDR properties of this cell line. MDR is an ever-increasing concern, one that constantly threatens anticancer management. In this regard, the ability of the combination treatment investigated in this study$\mathrm{UV}_{\mathrm{A}} \mathrm{Sens} / \mathrm{UV}_{\mathrm{A}}$ and SAHA - to overcome this resistance and induce cytotoxicity, regardless of the presence of the PGP drug efflux pump is an important and promising finding.

In addition, it was observed that the Epstein-Barr virus (EBV-) transformed, autologous B-lymphoblastoid cell line (LCL) was also sensitive to treatment. LCL cells are a transformed, immortalised cell line $[49,50]$ and as such can be grown for prolonged periods in vitro. While in comparison to K562 cells, an overall increase in resistance was noticed in these cells with respect to $\gamma \mathrm{H} 2 \mathrm{AX}$ immunofluorescence assays, pre-treatment with HDACi led to increased overall $\mathrm{UV}_{\mathrm{A}} \mathrm{Sens} / \mathrm{UV}_{\mathrm{A}}$-induced cytotoxicity. This was also observed in cell viability and apoptosis studies-where LCLs pretreated for 24 and 48 hours showed significant increase in apoptosis and marked decrease in viability at both time points. LCL cells are a transformed cell line, therefore having similar properties of a malignant cell line, including the ability to rapidly proliferate. Therefore, the findings in this study, whereby this cell line behaves in a similar way to K562 and CEM-CCRF cells, are not unexpected, and only further act to highlight the imminent potential of combination therapy $\left(\mathrm{UV}_{\mathrm{A}}\right.$ Sens/UV $\mathrm{UV}_{\mathrm{A}}$ and SAHA).
We investigated the effect of preincubation with the hydroxamic acid, SAHA on $\mathrm{UVA}_{\mathrm{A}}$ Sens/ $\mathrm{UV}_{\mathrm{A}}$-induced DNA double-strand breaks in 4 haematological cell lines. Overall, the findings in this project indicate that SAHA has synergistic activity, enhancing $\mathrm{UV}_{\mathrm{A}} \mathrm{Sens} / \mathrm{UV}_{\mathrm{A}}$-induced cytotoxicity. Broad-spectrum HDACi SAHA has shown to cause accumulation of hyperacetylated proteins, highlighting the possibility that their toxicity is associated with induction of histone hyperacetylation and modulation of gene transcription through chromatin remodelling, leading to the selective activation of genes associated with cell growth and survival [51]. The consequence of a more open, transcriptionally active chromatin conformation potentially results in and increased number of binding sites available for the $\mathrm{UV}_{\mathrm{A}}$ Sens moiety. This speculation was strengthened with findings from uptake studies which demonstrated a positive correlation between pre-incubation with SAHA and increased nuclear binding of $U_{\mathrm{A}}$ Sens, inferred from higher detection levels of nuclear fluorescence. Furthermore, SAHA induced significant increase in apoptosis and decrease in cell viability in all four haematological cell lines. Using $\gamma \mathrm{H} 2 \mathrm{AX}$ assays, combination treatment was assessed in multiple haematological cell lines, results demonstrating HDACi's ability to attenuate the effect of phototherapy and so highlighting the potential for combination therapy involving both SAHA and $\mathrm{UV}_{\mathrm{A}} \mathrm{Sens} / \mathrm{UV}_{\mathrm{A}}$ for the treatment of CTCL.

\section{Acknowledgments}

The support of the Australian Institute of Nuclear Science and Engineering (AINSE) is acknowledged. T. C. Karagiannis was the recipient of AINSE awards. A. L. Rodd is the recipient of Baker IDI Bright Spark top-up Australian, and AINSE post-graduate awards. Epigenomic Medicine Laboratory is supported by McCord Research. Supported in part by the Victorian Government's Operational Infrastructure Support Program. The authors would like to acknowledge the use of the facilities provided by Monash Micro Imaging AMREP and particularly the expert assistance from Drs. Stephen Cody and Iśka Carmichael. A. L. Rodd, K. Ververis, and T. C. Karagiannis declare that they have no direct financial relation with the commercial identities mentioned in this paper that might lead to a conflict of interest.

\section{References}

[1] R. Willemze, E. S. Jaffe, G. Burg et al., "WHO-EORTC classification for cutaneous lymphomas," Blood, vol. 105, no. 10, pp. 3768-3785, 2005.

[2] P. Ponte, V. Serrão, and M. Apetato, "Efficacy of narrowband UVB vs. PUVA in patients with early-stage mycosis fungoides," Journal of the European Academy of Dermatology and Venereology, vol. 24, no. 6, pp. 716-721, 2010.

[3] T. Krejsgaard, K. Kopp, E. Ralfkiaer et al., "A novel xenograft model of cutaneous T-cell lymphoma," Experimental Dermatology, vol. 19, no. 12, pp. 1096-1102, 2010.

[4] R. L. Edelson, "Cutaneous T cell lymphoma: mycosis fungoides, Sezary syndrome, and other variants," Journal of the American Academy of Dermatology, vol. 2, no. 2, pp. 89-106, 1980. 
[5] L. P. H. Yang, "Romidepsin: in the treatment of T-cell lymphoma," Drugs, vol. 71, no. 11, pp. 1469-1480, 2011.

[6] J. Y. Li, S. Horwitz, A. Moskowitz et al., "Management of cutaneous T cell lymphoma: new and emerging targets and treatment options," Cancer Management and Research, vol. 4, no. 1, pp. 75-89, 2012.

[7] S. Jain and J. Zain, "Romidepsin in the treatment of cutaneous T-cell lymphoma," Journal of Blood Medicine, vol. 2, no. 1, pp. 37-47, 2011.

[8] H. M. Prince and M. Dickinson, "Romidepsin for cutaneous T-cell lymphoma," Clinical Cancer Research, vol. 18, no. 13, pp. 3509-3515, 2012.

[9] F. Glass, K. L. Keller, J. L. Messina et al., "The diagnosis and treatment of cutaneous T-cell lymphoma are challenging due the many clnical and histopathologic presentations of the disease," Cancer Control, vol. 5, no. 1, 1998.

[10] E. Diamandidou, P. R. Cohen, and R. Kurzrock, "Mycosis fungoides and Sezary syndrome," Blood, vol. 88, no. 7, pp. 23852409, 1996.

[11] R. Knobler, M. L. Barr, D. R. Couriel et al., "Extracorporeal photopheresis: past, present, and future," Journal of the American Academy of Dermatology, vol. 61, no. 4, pp. 652-665, 2009.

[12] C. Q. Xia, K. A. Campbell, and M. J. Clare-Salzler, "Extracorporeal photopheresis-induced immune tolerance: a focus on modulation of antigen-presenting cells and induction of regulatory T cells by apoptotic cells," Current Opinion in Organ Transplantation, vol. 14, no. 4, pp. 338-343, 2009.

[13] J. Scarisbrick, "Extracorporeal photopheresis: what is it and when should it be used?" Clinical and Experimental Dermatology, vol. 34, no. 7, pp. 757-760, 2009.

[14] F. Hutchinson, "The lesions produced by ultraviolet light in DNA containing 5 bromouracil," Quarterly Reviews of Biophysics, vol. 6, no. 2, pp. 201-246, 1973.

[15] R. Rodriguez, E. Miller, J. F. Fowler et al., "Continuous infusion of halogenated pyrimidines," International Journal of Radiation Oncology, Biology, Physics, vol. 20, pp. 1380-1382, 1991.

[16] T. C. Karagiannis, P. N. Lobachevsky, B. K. Y. Leung, J. M. White, and R. F. Martin, "Receptor-mediated DNA-targeted photoimmunotherapy," Cancer Research, vol. 66, no. 21, pp. 10548-10552, 2006.

[17] T. C. Karagiannis, P. N. Lobachevsky, and R. F. Martin, "DNA targeted UVA photosensitization: characterization of an extremely photopotent iodinated minor groove binding DNA ligand," Journal of Photochemistry and Photobiology B, vol. 83, no. 3, pp. 195-204, 2006.

[18] R. F. Martin, D. P. Kelly, M. Roberts et al., "Comparative studies of UV-induced DNA cleavage by structural isomers of an iodinated DNA ligand," International Journal of Radiation Biology, vol. 66, pp. 517-521, 1994.

[19] R. F. Martin, D. P. Kelly, M. Roberts et al., "DNA cleavage by analogues of iodoHoechst 33258," Australian Journal of Chemistry, vol. 47, pp. 1751-1769, 1994.

[20] V. M. Richon, "Cancer biology: mechanism of antitumour action of vorinostat (suberoylanilide hydroxamic acid), a novel histone deacetylase inhibitor," British Journal of Cancer, vol. 95, no. 1, pp. S2-S6, 2006.

[21] J. Tan, S. Cang, Y. Ma, R. L. Petrillo, and D. Liu, "Novel histone deacetylase inhibitors in clinical trials as anti-cancer agents," Journal of Hematology and Oncology, vol. 3, article 5, 2010.

[22] B. S. Mann, J. R. Johnson, M. H. Cohen, R. Justice, and R. Pazdur, "FDA approval summary: vorinostat for treatment of advanced primary cutaneous T-cell lymphoma," Oncologist, vol. 12, no. 10, pp. 1247-1252, 2007.

[23] D. Siegel, M. Hussein, C. Belani et al., "Vorinostat in solid and hematologic malignancies," Journal of Hematology and Oncology, vol. 2, article 31, 2009.

[24] N. Batty, G. G. Malouf, and J. P. J. Issa, "Histone deacetylase inhibitors as anti-neoplastic agents," Cancer Letters, vol. 280, no. 2, pp. 192-200, 2009.

[25] C. B. Lozzio and B. B. Lozzio, "Human chronic myelogenous leukemia cell line with positive Philadelphia chromosome," Blood, vol. 45, no. 3, pp. 321-334, 1975.

[26] D. M. Woodcock, S. Jefferson, M. E. Linsenmeyer et al., "Reversal of the multidrug resistance phenotype with Cremophor EL, a common vehicle for water-insoluble vitamins and drugs," Cancer Research, vol. 50, no. 14, pp. 4199-4203, 1990.

[27] S. A. Bateman, D. P. Kelly, R. F. Martin, and J. M. White, "DNA binding compounds. VII synthesis, characterization and DNA binding capacity of 1,2-dicarba-closo-dodecaborane bibenzimidazoles related to the DNA minor groove binder Hoechst 33258," Australian Journal of Chemistry, vol. 52, no. 4, pp. 291301, 1999.

[28] L. J. Mah, A. El-Osta, and T. C. Karagiannis, " $\gamma \mathrm{H} 2 \mathrm{AX}$ as a molecular marker of aging and disease," Epigenetics, vol. 5, no. 2, pp. 129-136, 2010.

[29] L. J. Mah, R. S. Vasireddy, M. M. Tang, G. T. Georgiadis, A. ElOsta, and T. C. Karagiannis, "Quantification of gammaH2AX foci in response to ionising radiation," Journal of Visualized Experiments, no. 38, 2010.

[30] L. C. Sambucetti, D. D. Fischer, S. Zabludoff et al., "Histone deacetylase inhibition selectively alters the activity and expression of cell cycle proteins leading to specific chromatin acetylation and antiproliferative effects," Journal of Biological Chemistry, vol. 274, no. 49, pp. 34940-34947, 1999.

[31] T. C. Karagiannis, H. Kn, and A. El-Osta, "Disparity of histone deacetylase inhibition on repair of radiation-induced DNA damage on euchromatin and constitutive heterochromatin compartments," Oncogene, vol. 26, no. 27, pp. 3963-3971, 2007.

[32] J. Cadet, E. Sage, and T. Douki, "Ultraviolet radiation-mediated damage to cellular DNA," Mutation Research, vol. 571, no. 1-2, pp. 3-17, 2005.

[33] H. Lehrmann, L. L. Pritchard, and A. Harel-Bellan, "Histone acetyltransferases and deacetylases in the control of cell proliferation and differentiation," Advances in Cancer Research, vol. 86, pp. 41-65, 2002.

[34] P. A. Marks, R. A. Rifkind, V. M. Richon, R. Breslow, T. Miller, and W. K. Kelly, "Histone deacetylases and cancer: causes and therapies," Nature Reviews Cancer, vol. 1, no. 3, pp. 194-202, 2001.

[35] Y. Shao, Z. Gao, P. A. Marks, and X. Jiang, "Apoptotic and autophagic cell death induced by histone deacetylase inhibitors," Proceedings of the National Academy of Sciences of the United States of America, vol. 101, no. 52, pp. 18030-18035, 2004.

[36] G. Dong, L. Wang, C. Y. Wang, T. Yang, M. V. Kumar, and Z. Dong, "Induction of apoptosis in renal tubular cells by histone deacetylase inhibitors, a family of anticancer agents," Journal of Pharmacology and Experimental Therapeutics, vol. 325, no. 3, pp. 978-984, 2008.

[37] H. M. Amin, S. Saeed, and S. Alkan, "Histone deacetylase inhibitors induce caspase-dependent apoptosis and downregulation of daxx in acute promyelocytic leukaemia with 
t(15;17)," British Journal of Haematology, vol. 115, no. 2, pp. 287-297, 2001.

[38] T. Toyooka and Y. Ibuki, "Histone deacetylase inhibitor sodium butyrate enhances the cell killing effect of psoralen plus UVA by attenuating nucleotide excision repair," Cancer Research, vol. 69, no. 8, pp. 3492-3500, 2009.

[39] B. Briggs, K. Ververis, A. L. Rodd, L. J. L. Foong, F. M. D. Silva, and T. C. Karagiannis, "Photosensitization by iodinated DNA minor groove binding ligands: evaluation of DNA doublestrand break induction and repair," Journal of Photochemistry and Photobiology B, vol. 103, no. 2, pp. 145-152, 2011.

[40] K. L. Cann and G. G. Hicks, "Regulation of the cellular DNA double-strand break response," Biochemistry and Cell Biology, vol. 85, no. 6, pp. 663-674, 2007.

[41] A. Kinner, W. Wu, C. Staudt, and G. Iliakis, "Gamma-H2AX in recognition and signaling of DNA double-strand breaks in the context of chromatin," Nucleic Acids Research, vol. 36, no. 17, pp. 5678-5694, 2008.

[42] E. C. Friedberg, "DNA damage and repair," Nature, vol. 421, no. 6921, pp. 436-440, 2003.

[43] L. J. Mah, A. El-Osta, and T. C. Karagiannis, " $\gamma$ h2AX: a sensitive molecular marker of DNA damage and repair," Leukemia, vol. 24, no. 4, pp. 679-686, 2010.

[44] J. S. Dickey, C. E. Redon, A. J. Nakamura, B. J. Baird, O. A. Sedelnikova, and W. M. Bonner, "H2AX: functional roles and potential applications," Chromosoma, vol. 118, no. 6, pp. 683692, 2009.

[45] N. Kartner and V. Ling, "Multidrug resistance in cancer," Scientific American, vol. 260, no. 3, pp. 44-51, 1989.

[46] E. K. Baker and A. El-Osta, "The rise of DNA methylation and the importance of chromatin on multidrug resistance in cancer," Experimental Cell Research, vol. 290, no. 2, pp. 177-194, 2003.

[47] T. Litman, T. E. Druley, W. D. Stein, and S. E. Bates, "From MDR to MXR: new understanding of multidrug resistance systems, their properties and clinical significance," Cellular and Molecular Life Sciences, vol. 58, no. 7, pp. 931-959, 2001.

[48] A. F. List, K. J. Kopecky, C. L. Willman et al., "Benefit of cyclosporine modulation of drug resistance in patients with poor-risk acute myeloid leukemia: a Southwest Oncology Group study," Blood, vol. 98, no. 12, pp. 3212-3220, 2001.

[49] G. Miller and M. Lipman, "Comparison of the yield of infectious virus from clones of human and simian lymphoblastoid lines transformed by Epstein Barr virus," The Journal of Experimental Medicine, vol. 138, no. 6, pp. 1398-1412, 1973.

[50] J. Werner, G. Henle, C. A. Pinto, R. F. Haff, and W. Henle, "Establishment of continuous lymphoblast cultures from leukocytes of gibbons (Hylobates lar)," International Journal of Cancer, vol. 10, no. 3, pp. 557-567, 1972.

[51] M. J. Peart, K. M. Tainton, A. A. Ruefli et al., "Novel mechanisms of apoptosis induced by histone deacetylase inhibitors," Cancer Research, vol. 63, no. 15, pp. 4460-4471, 2003. 


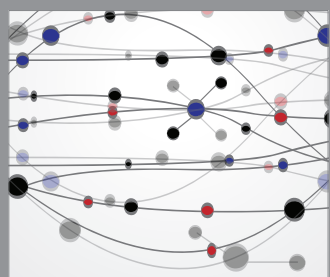

The Scientific World Journal
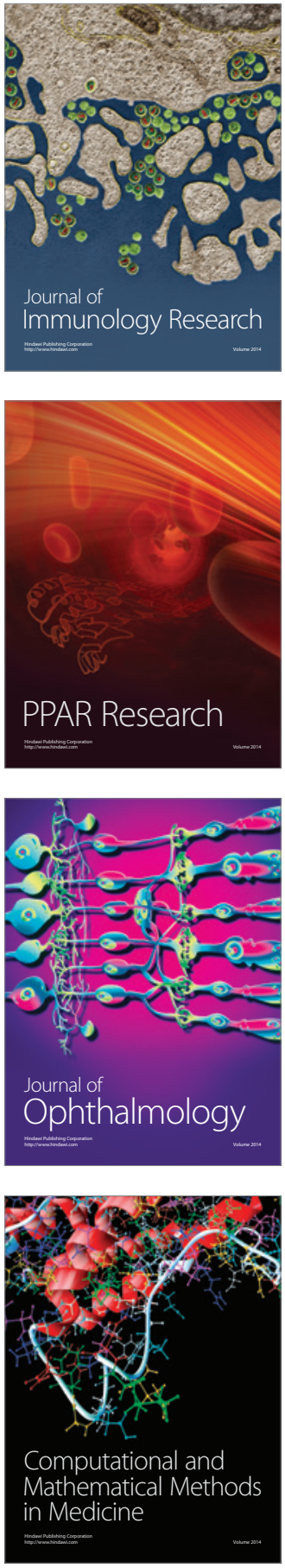

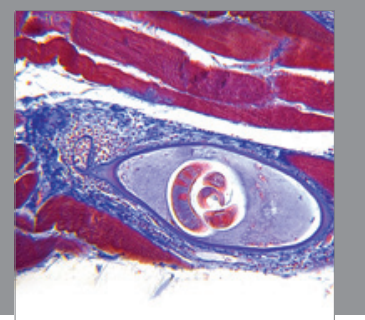

Gastroenterology

Research and Practice
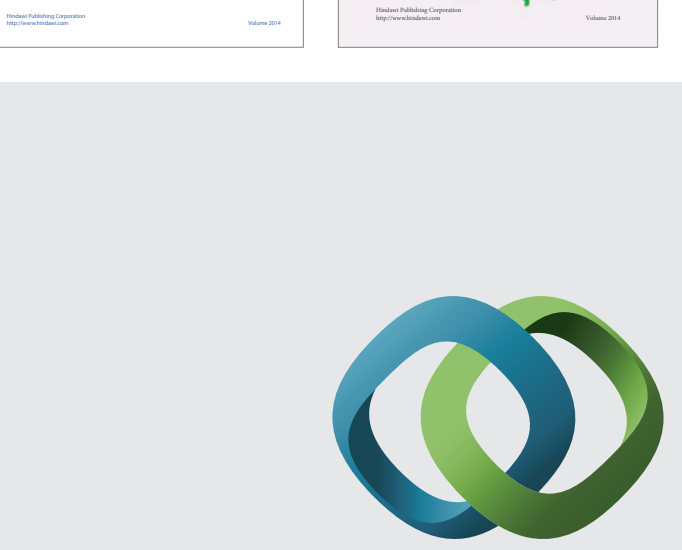

\section{Hindawi}

Submit your manuscripts at

http://www.hindawi.com
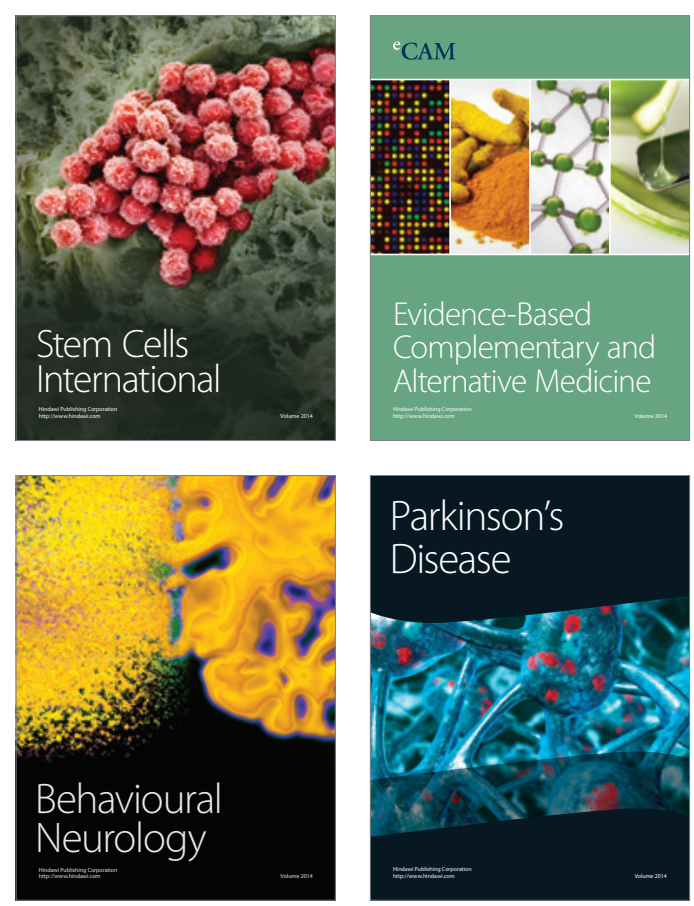

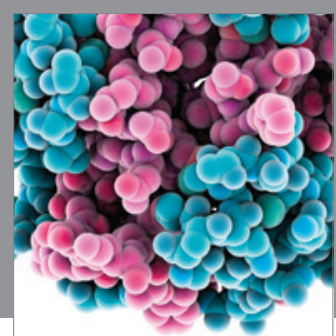

Journal of
Diabetes Research

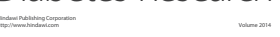

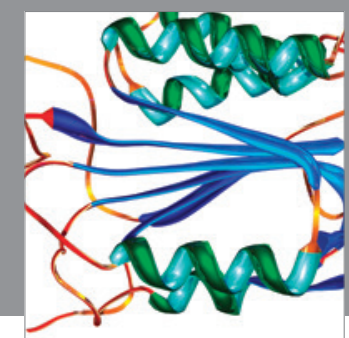

Disease Markers
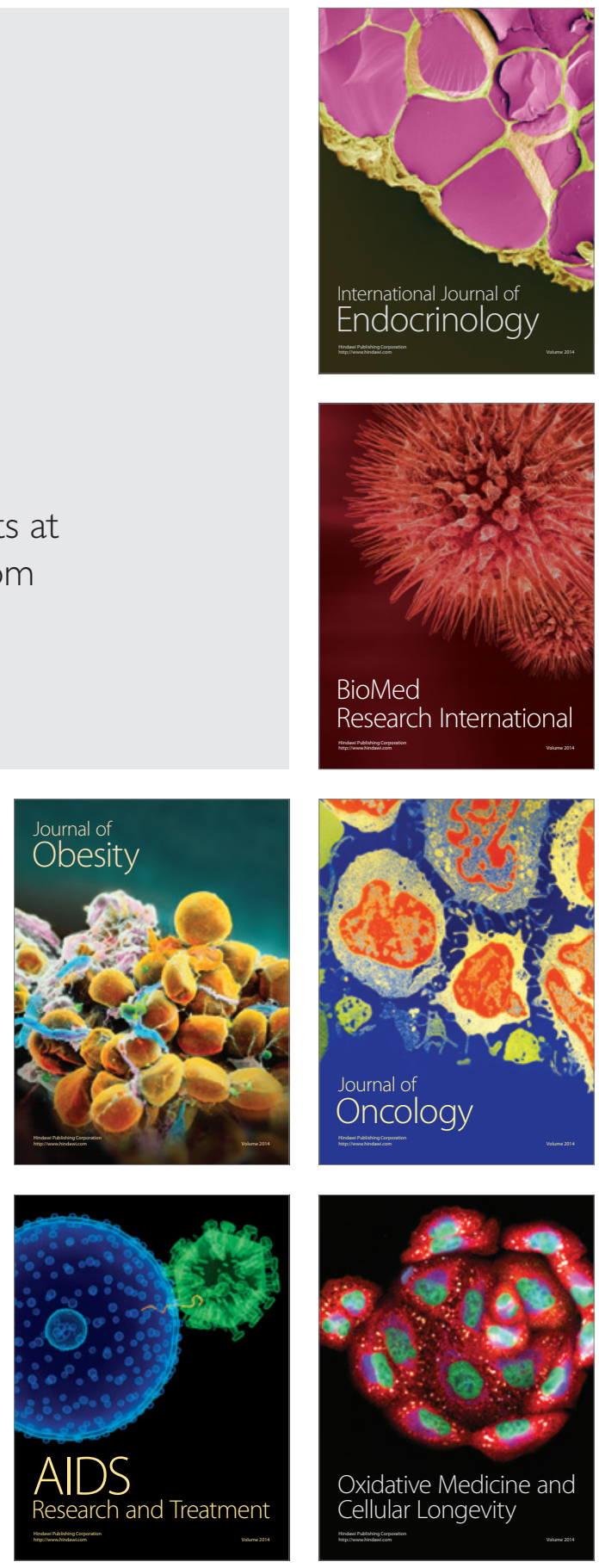